\title{
¿Vestuario o agencia? \\ Representación de género en cinco videojuegos de acción de la séptima generación*
}

\author{
Antonio Corona ${ }^{* *}$ \\ Recibido: 2018-09-02. Enviado a pares: 2018-09-15. \\ Aprobado por pares: 2018-11-03. Aceptado: 2018-11-28 \\ https://doi.org/10.22395/angr.v17n34a8
}

\begin{abstract}
Resumen
El presente trabajo realizó un estudio cuantitativo de la representación de género en cinco videojuegos de acción multiplataforma líderes en ventas de la séptima generación, mediante la técnica de análisis de contenido. Se analizó la totalidad de la narrativa central de cada uno de los títulos, utilizando el personaje como unidad de análisis y la misión como unidad de registro, entendiendo esta como cada sección del juego en la cual el jugador requiere lograr un objetivo para progresar en la narrativa. Se categorizaron la apariencia física, comportamiento, lenguaje y vestimenta de personajes primarios, secundarios y terciarios tanto masculinos como femeninos. El estudio encontró una proporción de 4,1 personajes masculinos por cada personaje femenino, lo cual constituye una grave subrepresentación del género femenino en estos títulos. También se encontraron diferencias significativas tanto de representación física como de comportamiento entre personajes masculinos y femeninos. En lo que respecta a la apariencia física, se encontró que los atuendos de los personajes femeninos son notablemente más reveladores que los de los personajes masculinos. En cuanto al comportamiento, se encontró en los personajes femeninos una mayor presencia de conductas sexualizadas y una menor seguridad, violencia y actitud de liderazgo que en sus contrapartes masculinos. Se comenta que, a pesar de lo encontrado, la representación de género en el medio ha mejorado con respecto a investigaciones realizadas con anterioridad, y que es necesario investigar la manera en que los jugadores se relacionan con estos contenidos.
\end{abstract}

Palabras clave: diversidad cultural; videojuego; género; sexualidad; hegemonía; representación; estereotipo sexual; medios de comunicación de masas.

Artículo de investigación realizado con el auspicio de la Universidad Autónoma de Coahuila, a partir de resultados del proyecto Representación étnica y de género en videojuegos multiplataforma llevado a cabo por el autor.

* Doctor en Estudios Humanísticos del Tecnológico de Monterrey, miembro del Sistema Nacional de Investigadores y de la Asociación Mexicana de Investigación de la Comunicación, docente e investigador de la Facultad de Ciencias de la Comunicación de la Universidad Autónoma de Coahuila, México. antoniocorona@uadec.edu.mx. Orcid: https://orcid.org/0000-0003-0094-5752 


\title{
Wardrobe or agency? Gender representation in 5 action videogames of the seventh generation
}

\begin{abstract}
This work conducted a quantitative study of gender representation in five top-selling multiplatform action video games leading in sales of the seventh generation, through the technique of content analysis. The central narrative of each game was analyzed by using the character as an analysis unit and the mission as a registration unit; the latter is taken as each section of the game in which the player needs to achieve a goal to progress through the story. The physical appearance, behavior, language and dress of both masculine and feminine leading, supporting and tertiary characters were categorized. A 4:1 ratio between male and female characters was found, which comprises a serious under-representation of the female gender in these games. Significant differences were also found in both physical and behavioral representation between male and female characters. Regarding physical appearance, it was found that female characters' outfits are noticeably more revealing than those of male ones. Concerning behavior, female characters were found to have a greater presence of sexualized behaviors and to have less confidence, violence and leadership attitude than their male counterparts. It is claimed that, despite what has been found, gender representation in the media has improved when compared to the findings of previous studies, and that it is necessary to do research on the way in which players relate to these contents.
\end{abstract}

Keywords: cultural diversity; videogame; gender; sexuality; hegemony; representation; sexual stereotype; mass media.

\section{Vestuário ou agência? Representação de gênero em cinco videogames de ação da sétima geração}

\begin{abstract}
Resumo
O presente trabalho realizou, por meio da técnica de análise de conteúdo, um estudo quantitativo da representação de gênero em cinco videogames de ação multiplataforma líderes em vendas da sétima geração. Analisou-se a totalidade da narrativa central de cada um dos títulos e utilizou-se o personagem como unidade de análise e a missão como unidade de registro - esta foi entendida como cada seção do jogo na qual o jogador precisa alcançar um objetivo para progredir na narrativa. Categorizou-se a aparência física, o comportamento, a linguagem e a vestimenta de personagens primários, secundários e terciários, tanto masculinos quanto femininos. O estudo encontrou uma proporção de 4,1 personagens masculinos para cada personagem feminino, o que constitui uma grave sub-representação do gênero feminino nesses títulos. Também foram encontradas diferenças significativas tanto de representação física quanto de comportamento entre personagens masculinos e femininos. No que diz respeito à aparência física, descobriu-se que a vestimenta dos personagens femininos é notavelmente mais reveladora que a dos personagens masculinos. Quanto ao comportamento, notou-se nos personagens femininos uma maior presença de condutas sexualizadas e menor segurança, violência e atitude de liderança do que em seus pares masculinos. Comenta-se que, apesar das descobertas, a representação de gênero no meio melhorou em comparação a pesquisas realizadas anteriormente e que é necessário analisar a maneira em que os jogadores se relacionam com esses conteúdos.
\end{abstract}

Palavras-chave: diversidade cultural; videogame; gênero; sexualidade; hegemonia; representação; estereótipo sexual; meios de comunicação de massas. 


\section{Introducción}

El fenómeno de los videojuegos en el continente americano se ha enmarcado desde sus inicios por una lógica de centro-periferia en la que el centro es Norteamérica, y particularmente los Estados Unidos. Al ser una de las tres mecas de la producción de videojuegos (junto con Japón y el norte de Europa) y contar con la base de consumidores más grande del continente, EUA se han afianzado firmemente como el centro económico y cultural de la industria del videojuego, y cada uno de los aspectos más importantes del videojuego como fenómeno cultural en el continente se enuncia en el contexto de un diálogo asimétrico entre este centro y sus múltiples periferias continentales.

En el resto del continente, el consumo de videojuegos ha crecido de manera vertiginosa, y cada vez más este consumo se lleva a cabo a través de canales formales: solo hace falta echar una mirada a las cifras publicadas por la industria de los videojuegos para darnos una idea de la dimensión de su consumo en la región: de acuerdo con el reporte del mercado global de videojuegos, realizado por Newzoo Games Market Research, dicho mercado tiene en Latinoamérica un crecimiento anual de 14,2\%, muy por encima del crecimiento global de $8 \%$ (Newzoo, 2015).

Los anteriores números no toman en cuenta ni el comercio informal ni la piratería, los cuales siguen estando muy vinculados con el acto de jugar en la región. México y Brasil se destacan del resto de los países de la región comercial de Latinoamérica con el 71 $\%$ del movimiento económico en este sector. En el consumo formal de videojuegos por volumen, México se ubica en el primer lugar de Latinoamérica y en el puesto 12 a nivel mundial con un consumo de 1.428 millones de dólares en el 2017 (Newzoo, 2017), lo cual nos indica un constante crecimiento, teniendo en cuenta el consumo de 1.006 millones en 2014 (Newzoo, 2015) y 8.600 millones en 2008 (Pro México, 2009).

Si tenemos en cuenta estas cifras, hay que concluir que la evidencia económica apunta al hecho de que el videojuego es una actividad importante en Latinoamérica. Así pues, resulta necesario llevar a cabo una reflexión respecto a la importancia de los mensajes contenidos en los videojuegos comerciales de mayor distribución en la región, y tomar acciones concretas para conocer el contenido de dichos mensajes.

Una gran parte de los estudios realizados en este sentido en diversas regiones del mundo coinciden en que el género es una de las áreas más problemáticas: los estudios que se han hecho al respecto muestran una clara tendencia a presentar mensajes hegemónicos en la representación de la mujer, mostrándola como víctima, indefensa sin la ayuda de una contraparte masculino (Provenzo, 1991) o presentándola como eye-candy, de manera erotizada y cosificada (objectified) (Beasley y Standley, 2002; Ivory, 2006). Los estudios más recientes al respecto muestran que, si bien los patrones de representación de género en el videojuego han cambiado (e incluso mejorado), la representación de la mujer en el medio tiene aún mucho camino que recorrer (Fisher, 2015; Kondrat, 2015; Lynch, Tompkins, Van Driel y Frtiz, 2016). 
Más allá de esto, desde principios de la década del 2010 la problemática de género en el videojuego ha pasado del videojuego como medio, al videojuego como comunidad. El escándalo conocido como gamergate es un triste ejemplo de la magnitud del problema de representación de género en la industria del videojuego y las comunidades de jugadores: a mediados del 2014, la diseñadora independiente de videojuegos Zoe Quinn y la crítica mediática Anita Sarkeesian, entre otras personas, fueron víctimas de una campaña de ataques sistemáticos (incluyendo amenazas de muerte y violación) cuya crudeza y dimensión terminó llamando la atención de la prensa secular (Kaplan, 2014).

Si bien los ataques se llevaron a cabo bajo pretextos de lucha por la ética periodística, quedó claro que la motivación fue reaccionaria, ante el creciente número de jugadores que busca una mayor diversidad de voces y de representación en la industria. Esta postura es percibida por algunos miembros de las comunidades de videojuegos como una amenaza al statu quo por el que siempre se han visto beneficiados (Kaplan, 2014; Stuart, 2014). Estos eventos, y la prevalencia en la comunidad del estereotipo de la chica gamer (girl gamer) (Harrison, Drenten y Pendarvis, 2016) nos ilustra el preocupante grado de otrificación del género femenino entre algunas comunidades de videojugadores.

Si se desea estudiar la manera en que los videojuegos representan la realidad y las identidades (y diferencias) que se forman y desenvuelven en dicha realidad, es menester tener en cuenta tanto el amplio bagaje de estudio académico sobre la identidad y su representación mediática, como la naturaleza particular del videojuego y las características que lo diferencian de otros medios. Para efectos de este estudio, la más importante de estas características es que, si bien el videojuego puede contener (y usualmente contiene) mensajes, estos no son parte inherente de la naturaleza del mismo, o como lo expresa Malaby, "el videojuego no tiene que lograr generar una historia para ser considerado como tal" (2007): la naturaleza re-iterativa del videojuego provoca que una gran cantidad del significado que se crea en el acto de juego no provenga de los elementos de narrativa tradicional insertos en el juego (elementos a los que llamamos narrativa prescrita), sino de la interacción repetida del jugador con el espacio diseñado por el creador (Bogost, 2008; Corona, 2015; 2016; Frasca, 2004). No quiere esto decir que no se creen significados también a partir de la narrativa prescrita, ni mucho menos que esta no forme parte de la experiencia de juego. Más bien, podríamos declarar que el videojuego consiste en una mezcla, a mayor o menor grado dependiendo del juego, de dos elementos: narrativa prescrita y gameplay. A pesar de que el gameplay es un concepto de suma importancia para el estudio de la significación y transmisión de mensajes en videojuegos, definir dicho concepto es complicado: Egenfeldt, Smith y Tosca (2008) definen gameplay como "la dinámica de juego que emerge de la interacción entre las reglas y la geografía del juego".

Comprendemos la otrificación (othering) como la reducción de aquellas personas que no comparten la propia identidad a una característica definitoria considerada como no deseable, y la esencialización de dicha característica (Ashcroft, Griffiths y Tiffin, 2013; Jensen, 2011; Powell y Menendian, 2016). El término original (othering) se ha traducido de diversas maneras. En opinión del autor, "otrificación" es la traducción que mejor captura la intención de origen, y el uso de esta práctica como un ejercicio de poder. 
Por su parte, Salen y Zimmerman (2004) lo definen como la "interacción formalizada que ocurre cuando el jugador sigue las reglas de un juego y experimenta su sistema mediante el juego". Si se busca un término operativo, es más sencillo definirlo mediante el contraste, es decir, diferenciándolo de lo que no es gameplay. Así, pueden entenderse como gameplay los elementos de interactividad del videojuego, es decir, a riesgo de caer en el simplismo, los momentos en que el jugador está jugando. En contraste, la narrativa prescrita - de acuerdo a la definición de Ip (2010) - comprende aquellos momentos en que el jugador se convierte en espectador: los cutscenes ${ }^{2}$, videos o textos en pantalla, que sirven para transmitir información sin la necesidad de interacción por parte del jugador, del mismo modo que un programa de televisión o una revista. De ahí que un videojuego, especialmente si tiene una gran carga narrativa, pueda ser entendido como un equilibrio de gameplay -el jugador jugando-y narrativa prescrita -el jugador como espectador-.

Es de vital importancia, sin embargo, tener en cuenta que la ausencia de narrativa prescrita para nada supone la ausencia de un mensaje discernible: ya Ip (2010) se encontró con esto en su análisis del juego Half-Life 2, muy aclamado entre los críticos de la industria por su calidad narrativa, al descubrir que solo el 1 \% del juego era codificable analizando únicamente la narrativa prescrita, pues no utiliza en lo absoluto cutscenes ni texto, sino que los significados que confiere emergen mediante las interacciones del personaje con su entorno. Al ser los videojuegos un medio configurativo, los significados no solo se extraen a partir de la narrativa, sino de la acumulación de interacciones con el espacio de juego (Frasca, 2004) y, específicamente, con los elementos significantes presentes en el mismo (Corona, 2017). Por lo tanto, confinar el potencial significante de los videojuegos al ámbito de la narrativa prescrita resultaría ser un grave error si queremos, como aquí se pretende, analizar los mensajes contenidos en su diseño.

En lo que se refiere al aspecto de la representación, podemos decir que, claramente, el contenido de los medios no puede ser considerado como una reproducción exacta de la realidad, sino como una codificación de dicha realidad, producto del contexto económico y sociocultural del emisor o codificador (Hall, 1980), y sujeto a una negociación constante al nivel de instituciones, textos y audiencias (Fiske, 1991). Los textos mediáticos, por lo tanto, no contienen un solo significado, sino que son polisémicos (Fiske, 1987) y no construyen roles étnicos y de género definidos y grabados en piedra, sino articulaciones divergentes e incluso conflictuadas (Van Zoonen, 1991). A pesar de esto, la capacidad de polisemia en el mensaje no es infinita, sino que es afectada por los límites establecidos por el emisor (Hall, 1980), el cual favorece un mensaje preferente.

El definir que la polisemia de un mensaje está limitada por la intención original del emisor es de vital importancia para el estudio del contenido de los videojuegos, dado que estos son un medio inherentemente polisémico, en que la interacción del jugado con el medio puede generar significados divergentes, e incluso contrarios a la lectura preferente. Sin embargo, más allá de la polisemia del medio, al jugador común le es imposible esca-

2 Secuencias de estilo cinematográfico en las cuales el jugador no tiene control sobre el juego, cuya finalidad es avanzar la narrativa. 
parse de los límites establecidos por el diseñador del juego, por lo cual siempre existirá un mensaje preferente discernible.

La metáfora del cazador furtivo, acuñada por Michel de Certeau (1984) y retomada por Jenkins (1992), es de especial ayuda para comprender la relación entre el jugador y el creador en el videojuego como medio de comunicación: el jugador tiene capacidad de agencia ${ }^{3}$ en su búsqueda y creación de significados, pero siempre estará sujeto a los límites rígidos establecidos por el autor. Si bien existen ciertas avenidas de agencia (e incluso de rebelión) para el jugador, como las modificaciones o mods (Dyer y De Peuter, 2009), estas generalmente se encuentran confinadas al ámbito del juego en PC, mientras que los usuarios de consolas comerciales no tienen acceso a estas posibilidades. Por lo tanto, para efectos de esta investigación, podemos establecer el hecho de que el trabajo de diseño del creador (y los límites que este establece) tiene un papel preponderante en la construcción de significado del acto de juego.

\section{Metodología}

La técnica utilizada fue el análisis de contenido. El criterio utilizado para elegir la muestra de videojuegos fue el siguiente: se hizo una lista de aquellos juegos multiplataforma (es decir, aquellos que pueden ser adquiridos en una o más plataformas diferentes, siendo estas consolas, computadoras o dispositivos portátiles) más vendidos de la séptima generación ${ }^{4}$. La utilización de la cantidad de ventas como indicador se debe al hecho de que las grandes desigualdades en la distribución y desempeño comercial en este medio provoca una diferencia de órdenes de magnitud entre la presencia de los títulos más exitosos y la del resto. Para la selección de los videojuegos se utilizaron cifras de ventas al primero de diciembre del 2010. Se tomaron de dicha lista solamente los juegos de acción y sus subgéneros por ser este el de mayor carga narrativa (Ip, 2010) y con mayor cantidad de títulos (Ip y Jacobs, 2006). En segundo término, en el caso de los títulos pertenecientes a series o franquicias, se retuvo solamente el juego más vendido de cada una y se eliminó el resto. Por ejemplo, los títulos Call of Duty: Modern Warfare y Call of Duty: World at War fueron eliminados, permanecieron en la lista solamente Call of Duty: Modern Warfare 2, el título más vendido de la serie hasta el momento de comienzo del estudio. En la tercera etapa, se retiró de la lista a aquellos títulos con menos de un millón de copias vendidas en alguna de las plataformas, con el propósito de evitar juegos cuyo alto tiraje se debió a su venta en paquetes junto con una consola, lo cual pone en duda la popularidad del título en sí mismo. Como última etapa, se retiró de la lista a los juegos con ventas totales menores a 6 millones de copias, con la finalidad de hacer la selección más manejable. El

3 Comprendiendo "agencia" como la capacidad socialmente determinada de ejercer cambio sobre el entorno (Corona, 2016). En casos de posible confusión, este concepto es mencionado como "agencia social" para distinguirla de la "agencia del jugador" (player agency), un concepto en teoría de diseño de videojuegos que se refiere a la capacidad del jugador de hacer cambios sobre el juego de acuerdo con las avenidas de acción permitidas por el diseñador.

$4 \quad$ La séptima generación de videojuegos generalmente es definida como la generación iniciada a partir del lanzamiento de la plataforma Xbox 360 en noviembre del 2005 (Nichols, 2013); sin embargo, dado que la intención de la investigación fue estudiar títulos disponibles en más de una plataforma, para efectos de la misma se establece el inicio de la séptima generación a partir de marzo del 2007, en que las tres consolas principales estuvieron disponibles globalmente. 
resultado final del proceso fueron cinco títulos, presentados a continuación junto con las plataformas en las que fueron lanzados y sus ventas totales al 1 de diciembre de 20105:

- Call of Duty: Modern Warfare 2 (Xbox 360, Playstation 3, PC): 21,38

- Grand Theft Auto IV (Xbox 360, Playstation 3, PC): 16,32

- Assassin's Creed II (Xbox 360, Playstation 3): 8,22

- Red Dead Redemption (Xbox 360, Playstation 3): 6,64

- Resident Evil 5 (Xbox 360, Playstation 3): 6,29

Para llevar a cabo el análisis de contenido, se utilizó como unidad de análisis al personaje. Con el objetivo de medir la sexualización de los personajes, se utilizaron variables inspiradas en las categorizaciones de Beasley y Standley (2002) y Downs y Smith (2009), enfocadas en el vestuario y el físico del personaje. Entre las variables de vestuario se codificaron las prendas superiores e inferiores de cada personaje de acuerdo a la proporción del cuerpo que se encuentre cubierta o descubierta. Las variables utilizadas fueron: mangas, cuello, cintura y prenda inferior. En mangas se utilizaron cuatro valores posibles: larga, es decir, del hombro a la muñeca. 3/4, equivalente a un largo de manga que va más allá del codo, pero no llega a la muñeca. Corta, equivalente a una manga que no llega al codo, y sin mangas. Para el caso del cuello, se utilizó cuello alto (el atuendo del personaje cubre el cuello totalmente), cuello bajo, (el atuendo llega a la base del cuello), cuello medio (el atuendo no llega al cuello, pero no muestra el pecho o pectorales del personaje), escote (el atuendo muestra una parte de los pechos en caso de personaje femenino o pectorales en caso de personaje masculino) y ninguno, en caso de que el personaje no utilice prenda superior. Para la variable cintura se codificó la presencia de cintura, cadera o vientre descubiertos por separado. La variable prenda inferior se utilizaron los valores cubierto (el atuendo cubre las piernas totalmente), debajo de la rodilla, a la rodilla, arriba de la rodilla, muslo superior (el atuendo deja descubiertos los muslos casi hasta los glúteos. Atuendos como hot pants, short-shorts o microfaldas entran en esta categoría) y bikini (el atuendo solo cubre el área genital y los glúteos total o parcialmente).

En las variables de físico se codificó la complexión del personaje, así como aquellas características físicas comúnmente ligadas con el atractivo personal en la cultura occidental, tales como el tamaño de los pechos en caso de personajes femeninos y la musculatura en ambos sexos. Siguiendo el ejemplo de Beasley y Standley (2002), estas variables fueron categorizadas mediante consenso entre dos codificadores, un hombre y una mujer, para evitar sesgos de apreciación. En el caso de complexión se utilizaron los valores débil, regular, musculoso y obeso. En el caso del pecho, se utilizaron los valores pequeño, regular y voluptuoso.

Las ventas totales son expresadas en millones de unidades y fueron consultadas en http://gamrreview.vgchartz.com/. La utilización de números arábigos o romanos en los títulos de los videojuegos corresponde al estilo utilizado en la portada de cada uno. 
En el caso del análisis de comportamiento, se dividieron las variables en los grupos violencia, lenguaje y actitud. En el grupo de violencia, se analizó la existencia de acciones violentas de cada personaje codificado, especificando si dichos actos constituyen violencia justificada. Se comprendió por violencia justificada aquella en que la narración no califica al acto violento como moralmente malo o indeseable debido al contexto y la presencia de circunstancias mitigantes (defensa propia, protección de seres queridos, deseo de justicia, etc.). Violencia injustificada, por otro lado, es comprendida como aquellos actos violentos sobre los cuales la narración no ofrece ningún factor mitigante. Se especificó de igual modo si los actos de violencia son incurridos durante los períodos de gameplay, en que el personaje es controlado directamente por el jugador, o en cutscenes, fuera del control de este.

En el aspecto del lenguaje se codificó la presencia de lenguaje violento (entendiendo a este como descripciones de actos violentos, ya sea como amenaza, recuerdo o fantasía), palabras altisonantes o vulgares y lenguaje sexual explícito o implícito. Se consideró lenguaje sexual implícito al uso del personaje de lenguaje con connotaciones o subtexto sexual, o que puede ser comprendido sexualmente, sin hacer referencias explícitas. Por lenguaje sexual explícito se consideró la referencia verbal directa a acciones o conductas sexuales, ya sea como proposición, reminiscencia o fantasía.

En la división de conducta, se codificaron actitudes de seguridad o inseguridad, comprendiendo las primeras como situaciones en que el personaje muestre seguridad o confianza en sí mismo, e inseguridad, como situaciones en que muestre inseguridad o falta de confianza. Asimismo, se codificaron las instancias en las que el personaje mostró actitud de liderazgo (resolviendo problemas o situaciones adversas, llevando a cabo acciones heroicas o constituyéndose como líder de un grupo). Se categorizaron también las instancias en las que el personaje lleva a cabo comportamientos sexualizados no verbales, entendiendo estos como conductas que invitan a otro personaje a llevar a cabo o contemplar la idea de una interacción sexual.

Se retomó también la variable recompensa verbal por sexualidad de Downs y Smith (2009), para referirse a los halagos recibidos debido a la apariencia física o manera de vestir. Se incluyeron también, sin embargo, situaciones en que el personaje recibe trato preferencial o consigue sus objetivos debido a su apariencia física o vestuario.

Como ya se ha mencionado, se utilizó como unidad de análisis el personaje. Dicho esto, el estudio requirió la definición de una unidad de registro, siguiendo lo planteado por Krippendorff (2004) con la finalidad de hacer más confiables y precisos los resultados: dado que la medición de variables de comportamiento requiere un análisis de la actitudes y acciones de los personajes durante toda la duración del videojuego, es necesario hacer una segmentación del contenido en unidades manejables, equivalente a lo que constituiría una división por escena en cine o televisión, sin embargo, debido a la estructura de los videojuegos, en la cual se suceden actividades interactivas y secuencias cinemáticas (donde el jugador no tiene control sobre su personaje y se convierte en un espectador), resulta 
difícil implementar la definición tradicional de escena utilizada en el cine y la televisión. Beasley y Standley (2002) y Downs y Smith (2009) resolvieron este problema dividiendo los videojuegos en segmentos de 20 minutos, no obstante, el problema de esta aproximación es el hecho de que dicha unidad de análisis es arbitraria y no corresponde a ninguna división natural en un medio que cuenta con una segmentación única y muy diferente a la de los medios tradicionales (Zagal, Fernández-Vara y Mateas, 2005). Por lo demás, el contenido de dichos segmentos de 20 minutos cambiaría de jugador dependiendo de la pericia y estilo de juego de cada uno, lo cual afecta la confiabilidad del estudio. Debido a esto, para objeto de esta investigación se sustituyó la escena tradicional por la misión. Se comprendió como misión cada sección del juego en la cual el jugador requiere lograr un objetivo para progresar en la narrativa ${ }^{6}$. Una vez que el jugador consigue este objetivo, la narrativa continúa su desarrollo y proporciona al jugador un nuevo objetivo. Debido a la estructura particular del videojuego, esta unidad de contexto es más fácilmente identificable que la escena, y menos propensa a resultar problemática durante las pruebas de confiabilidad.

En el caso de algunos juegos, la división por misiones es clara e inconfundible. En otros casos, esta división es más tenue y no se hace alusión directa a ella, pero la estructura en misiones está presente y es posible identificarla con relativa facilidad. En el caso de los videojuegos pertinentes a esta investigación, se encontró que todos ellos están divididos en misiones de manera explícita y evidente, e incluso se hace saber al jugador el nombre de cada misión al comenzar esta.

En cada misión, se asignó un valor a cada personaje involucrado de acuerdo con sus acciones y actitudes en la misma, sobre una escala de 1 a 5 correspondiente a la frecuencia del comportamiento medido. Los valores para cada variable de comportamiento fueron sumados y divididos entre el total de misiones del personaje, obteniéndose así una media total de 1 a 5 para cada variable de comportamiento del personaje.

La codificación fue hecha por un jugador experimentado en una consola Playstation 3. Aquellas escenas problemáticas por su rapidez o densidad de contenido fueron grabadas en video para su posterior análisis detallado. Las misiones opcionales, cuyo cumplimiento no es necesario para avanzar la narrativa principal del videojuego, no fueron tomadas en cuenta para el análisis de contenido, dado que no están necesariamente incluidas en la experiencia del jugador. Se siguió el mismo criterio para descartar aquellas misiones que constituyen "contenido exclusivo," es decir, que están presentes en la versión del juego para una plataforma, pero no para las demás. Se analizaron todas las misiones (exceptuando los casos mencionados arriba) de cada uno de los videojuegos seleccionados. Se llevó a cabo una prueba de confiabilidad entre dos codificadores para validar el instrumento y el procedimiento de codificación, obteniendo un grado de acuerdo superior al 80 \% en cada una de las categorías de estudio.

Cabe mencionar aquí que no se debe confundir el concepto de misión con el de nivel, ya que este último constituye dentro de la estructura del videojuego una división física o geográfica y no una división de gameplay (Zagal, FernándezVara y Mateas, 2005). 


\section{Resultados}

La primera parte de la investigación indagó la distribución de género en los personajes de los videojuegos seleccionados, con la finalidad de hacer una comparación de la misma con la distribución de población en los Estados Unidos. Se utilizó la población de los Estados Unidos por ser este el mercado meta del producto en el proceso de localización (Corona, 2012) ${ }^{7}$. Para este efecto, en primera instancia se dividió la población total de personajes por sexo. En segunda instancia, se llevó a cabo la misma división para personajes primarios, secundarios y terciarios (tabla 1).

Tabla 1. Frecuencia de representación general

\begin{tabular}{lcc}
\hline & Frecuencia & Porcentaje \\
\hline Sexo & & \\
\hline Masculino & 131 & $80,4 \%$ \\
\hline Femenino & 32 & $19,6 \%$ \\
\hline Total & 163 & $100 \%$ \\
\hline
\end{tabular}

Fuente: elaboración propia

Como muestra la tabla 1, la división del total de los personajes por sexo arrojó un $80 \%$ de personajes masculinos contra un $20 \%$ de femeninos, o una proporción de 4,10 hombres por cada mujer. El Buró de Censos de los Estados Unidos (2016) proyecta, en su base de datos del 2015, un 49,2 \% de población masculina y un 50,8 \% de población femenina (Buró de Censos, 2016). Por otro lado, de acuerdo con las cifras de la Entertainment Software Association, el 45 \% de los videojugadores en Estados Unidos son mujeres (ESA, 2018). Así pues, es posible apreciar una subrepresentación de género considerable en los videojuegos seleccionados al compararlos con la distribución real de la población en el mercado meta de los mismos. La investigación de Williams, Martins, Consalvo e Ivory (2009) obtuvo resultados relativamente similares, al estudiar videojuegos lanzados entre febrero del 2005 y marzo del 2006. Entre otras cosas, Williams et al. encontraron una distribución de personajes de $81,24 \%$ masculinos y $18,76 \%$ femeninos sobre una muestra de todos los videojuegos lanzados en ese lapso. Al sopesar los datos de acuerdo a la popularidad de cada título, encontraron que en los videojuegos más vendidos la brecha se ensanchaba a la razón de 85,23\% contra 14,77 \% . La proporción encontrada $(80,4 / 19,6)$ es muy parecida a la cifra de Williams et al. respecto a su muestra inicial $(81,24 / 18,76)$.

Los videojuegos a la venta en México corresponden a la zona Norteamérica de distribución de la industria, de la cual los Estados Unidos son el centro comercial. Tanto los videojuegos estadounidenses como aquellos producidos en otros países son localizados para su consumo en EUA (Carlson y Corliss, 2011; Consalvo, 2006). Este proceso de localización, como se ha discutido en otras instancias (Corona, 2012), implica la adición de elementos propios de la cultura del mercado meta (EUA en este caso) y la remoción de cualquier elemento que pueda herir las sensibilidades de dicho mercado. Dado que México, como se dijo, es parte de la región Norteamérica de distribución, los videojuegos consumidos en el país son localizados específicamente para el mercado estadounidense. 
Tabla 2. Frecuencia de representación por rol de personajes masculinos y femeninos

\begin{tabular}{lcccc}
\hline & \multicolumn{3}{c}{ Masculino } & Femenino \\
\hline Primario & 21 & $16 \%$ & 4 & $12,5 \%$ \\
\hline Secundario & 26 & $19,8 \%$ & 6 & $18,8 \%$ \\
\hline Terciario & 84 & $64,1 \%$ & 22 & $68,8 \%$ \\
\hline Total & 131 & $100 \%$ & 32 & $100 \%$ \\
\hline Controlable & 11 & Rol mecánico & & $3,1 \%$ \\
\hline No controlable & 120 & $8,4 \%$ & 1 & $96,9 \%$ \\
\hline Total & 131 & $91,6 \%$ & 31 & $100 \%$ \\
\hline
\end{tabular}

Fuente: elaboración propia

\section{Agrupación por rol narrativo y mecánico}

Al subdividir a los personajes en grupos de rol narrativo y mecánico, se encontró que, en el caso de la proporción hombre/mujer, la disparidad aumenta entre los personajes primarios. La disparidad disminuye para los personajes secundarios y es aún menor en el caso de los personajes terciarios, como se puede apreciar en la tabla 2. La misma tabla muestra la proporción de sexos entre los personajes de acuerdo al rol mecánico. En este caso, se encontró que, entre los personajes no controlables por el jugador, el porcentaje de mujeres es 20,53, mientras que entre los controlables es solo 8,33.

Tanto en el caso del rol narrativo como en el del rol mecánico, el porcentaje de personajes femeninos es menor entre los personajes de mayor importancia, y mayor entre los de menor importancia. Dicho esto, cabe recordar que aún entre los personajes menos importantes, la proporción de mujeres es mucho menor a la de la población.

La baja representación proporcional de mujeres y su confinamiento a roles secundarios coinciden con lo encontrado por distintas investigaciones hechas en generaciones de videojuegos anteriores (Glaubke, Miller, Parker y Espejo, 2001; Provenzo, 1991; Williams, Martins, Consalvo e Ivory, 2009). Así pues, el mundo representado por el videojuego pareciera seguir siendo un mundo eminentemente masculino, en que la mujer tiene muy poca injerencia. Un ejemplo extremo de esto se encuentra en el videojuego Call of Duty: Modern Warfare 2, en el que no aparece un solo personaje femenino. Aunque pudiera argumentarse que dicha omisión se debe a la temática del videojuego (un conflicto armado internacional), se debe tener en cuenta que el personal femenino constituye el 15,9\% de las fuerzas armadas de los Estados Unidos (Department of Defense, 2016) y el 10,1 \% de las fuerzas armadas del Reino Unido (Dempsey, 2017), por lo que la distribución de género del videojuego en cuestión no refleja para nada la constitución de las fuerzas armadas que representa. 


\section{Apariencia}

Haciendo el análisis de las seis variables codificadas respecto a la apariencia de los personajes (tabla 3), dos de dichas variables (largo de mangas y escote) son significativamente diferentes entre personajes femeninos y masculinos. Cabe mencionar que los valores posibles de esta variable van del 1 al 5 , en donde 5 equivale a la mayor exposición de piel posible. En este caso, los personajes femeninos tuvieron en promedio vestimentas tanto de mangas más breves como de escote más pronunciado.

Tabla 3. Prueba T, vestimenta de personajes masculinos y femeninos

\begin{tabular}{lcccccc}
\hline & \multicolumn{2}{c}{ Mangas } & \multicolumn{2}{c}{ Escote } & \multicolumn{2}{c}{ Prenda inferior } \\
\hline Sexo & $\mathrm{N}$ & Media & $\mathrm{N}$ & Media & $\mathrm{N}$ & Media \\
\hline Masculino & 131 & 1,29 & 128 & 2,07 & 12 & 1,11 \\
\hline Femenino & 32 & $\mathbf{1 , 7 5}$ & 32 & $\mathbf{3 , 1 3}$ & 32 & 1,43 \\
\hline T & $-2,27$ & - & - & - & - & - \\
\hline Significancia & 0,029 & - & 0,000 & - & 0,0 & - \\
\hline
\end{tabular}

Nota: todas las medias son de una escala del 1 al 5.

Fuente: elaboración propia

Así pues, se encontró una tendencia a representar a las mujeres en atuendos más reveladores, lo cual corrobora los hallazgos de varios estudios anteriores (Díez, Fontal y Blanco, 2004; Leonard, 2006; Glaubke et al., 2001). La tendencia al vestuario más breve en los personajes femeninos es un síntoma de sexualización, pero también de la presentación de dichos personajes como poco importantes o poco serios. Un ejemplo de esto puede ser encontrado en el videojuego Resident Evil 5, en el que se encuentran dos personajes femeninos importantes en papeles protagónico y antagónico, respectivamente. Ambos personajes, a pesar de ser importantes en el desarrollo de la trama, se encuentran supeditados a sendos personajes masculinos, y ambos personajes visten atuendos que no concuerdan con sus circunstancias (una crisis epidemiológica en África), mientras que sus contrapartes masculinas visten de manera más intuitiva. Aunque no se menciona en la trama del juego ninguna razón para este vestuario de cuestionable utilidad en el contexto, es claro que la razón ulterior del mismo es satisfacer visualmente al jugador. 


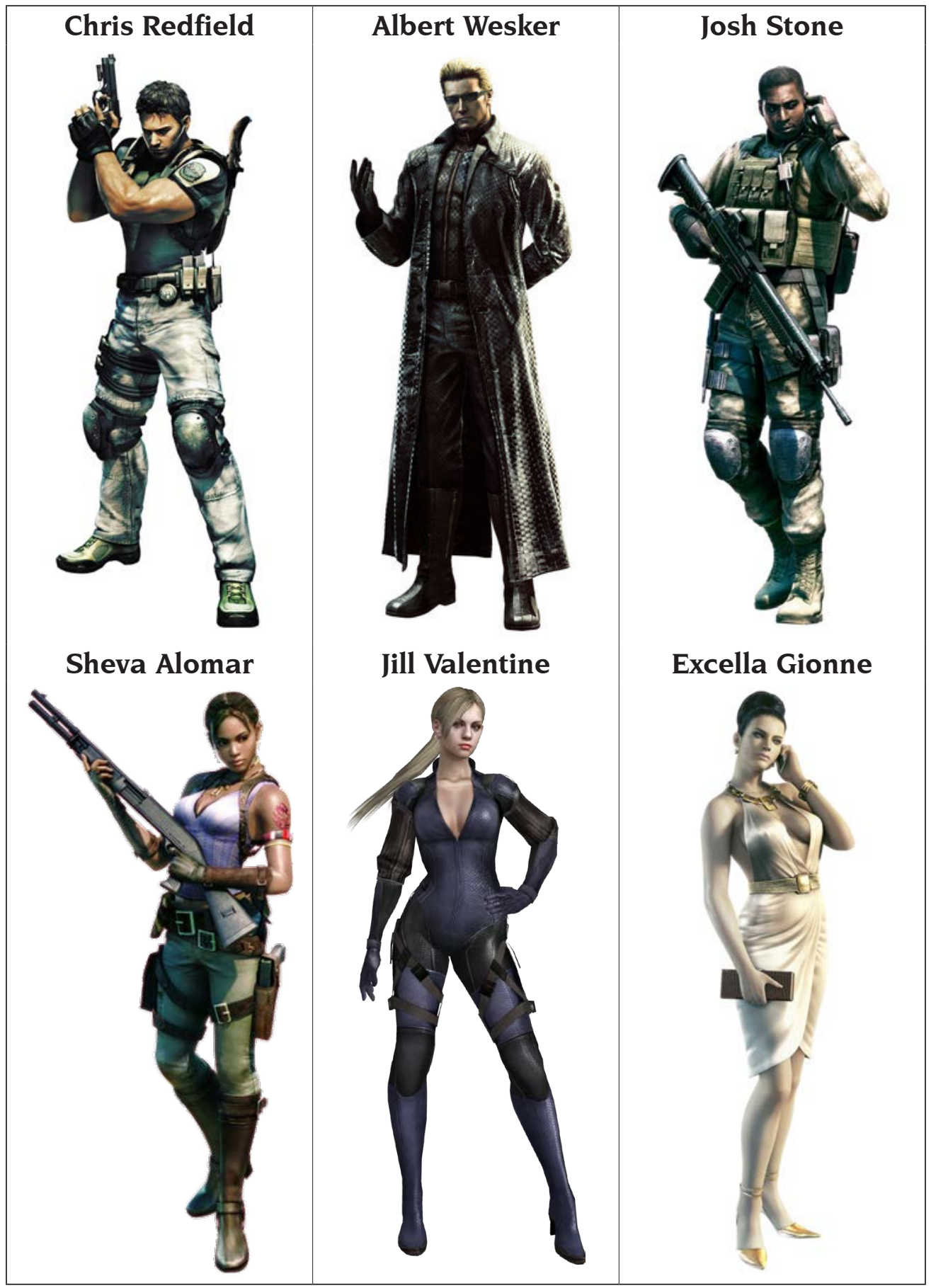

Figura 1. Vestimenta predeterminada por personaje, Resident Evil 5 Fuente: elaboración propia, utilizando material promocional de Capcom Co., Ltd. 


\section{Comportamiento}

En lo que respecta al comportamiento violento, se encontró menos incidencia entre los personajes femeninos tanto en violencia física como en lenguaje violento y palabras altisonantes. Específicamente, se encontró una media de 1,26 para mujeres y 1,92 para hombres en el renglón de violencia física. En el caso de lenguaje violento la media de los personajes femeninos fue solo de 1,15 contra 1,64 de personajes masculinos, mientras que la media de palabras altisonantes es de 1,58 de los hombres contra 1,20 de las mujeres (tabla 4).

Tabla 4. Prueba T, actitudes violentas de personajes masculinos y femeninos

\begin{tabular}{ccccccccc}
\hline & \multicolumn{2}{c}{ Violencia } & \multicolumn{2}{c}{$\begin{array}{c}\text { Justificadal } \\
\text { Injustificada }\end{array}$} & \multicolumn{2}{c}{$\begin{array}{c}\text { Lenguaje } \\
\text { violento }\end{array}$} & \multicolumn{2}{c}{$\begin{array}{c}\text { Palabras } \\
\text { altisonantes }\end{array}$} \\
\hline N & Media & N & Media & N & Media & N & Media \\
\hline Sexo & & & & & & & & \\
\hline Masculino & 130 & $\mathbf{1 , 9 2}$ & 76 & 2,86 & 131 & $\mathbf{1 , 6 4}$ & 131 & $\mathbf{1 , 5 8}$ \\
\hline Femenino & 32 & 1,26 & 6 & 3,47 & 32 & 1,15 & 32 & 1,20 \\
\hline T & 4,22 & - & $-0,81$ & - & 5,00 & - & 3,01 & - \\
\hline Significancia & 0,000 & - & 0,420 & - & 0,000 & - & 0,003 & - \\
\hline
\end{tabular}

Nota: todas las medias son de una escala del 1 al 5.

\section{Fuente: elaboración propia}

La representación de la mujer como menos violenta que el hombre es algo que se ha encontrado con anterioridad en los videojuegos (Bonder, 2002; Díez et al., 2004; Dill y Thill, 2007). La interpretación de dicha representación, sin embargo, no es tan clara: si bien es cierto que, por un lado, la representación de la mujer como víctima de violencia más que como perpetradora de la misma puede fomentar la idea de la mujer como indefensa o como damisela en apuros, también es cierto que otras perspectivas pueden argüir que la representación de la mujer como violenta sería por su parte un estereotipo perjudicial. Algunos autores incluso han abanderado ambas posiciones al mismo tiempo (Díez et al., 2004). Esto no quiere decir que ambos estereotipos no puedan coexistir, como de hecho muchos estereotipos contradictorios coexisten en un mismo texto (Rico McPato que es al mismo tiempo explotador y filantrópico en el estudio de Mattelart, por citar un ejemplo clásico).

De manera contrastante, se encuentra que en el aspecto de comportamiento sexual, la media de lenguaje sexual implícito y la de conducta sexualizada son superiores para los personajes femeninos. Teniendo en cuenta que un personaje sin ningún tipo de lenguaje o comportamiento sexual sería codificado como 1,00, es posible apreciar aquí que, mientras los personajes masculinos se encuentran cerca de dicha cifra, los femeninos están más alejados. Por otro lado, en el aspecto de lenguaje sexual explícito, personajes masculinos 
y femeninos se encuentran muy cerca tanto unos de otros como de la cifra mínima, con 1,02 para hombres y 1,01 para mujeres (tabla 5).

Tabla 5. Prueba T, actitudes sexuales de personajes masculinos y femeninos

\begin{tabular}{ccccccccc}
\hline & $\begin{array}{c}\text { Lenguaje sexual } \\
\text { implícito }\end{array}$ & \multicolumn{2}{c}{$\begin{array}{c}\text { Lenguaje sexual } \\
\text { explícito }\end{array}$} & $\begin{array}{c}\text { Recompensa por } \\
\text { sexualidad }\end{array}$ & Conducta sexualizada \\
\hline N & Media & $\mathrm{N}$ & Media & $\mathrm{N}$ & Media & $\mathrm{N}$ & Media \\
\hline Sexo & & & & & & & & \\
\hline Masculino & 131 & 1,03 & 131 & 1,02 & 131 & 1,00 & 131 & 1,04 \\
\hline Femenino & 32 & 1,26 & 32 & 1,01 & 32 & 1,00 & 32 & 1,37 \\
\hline T & $-1,75$ & - & 0,63 & - & 0,188 & - & $-2,06$ & - \\
\hline Significancia & 0,088 & - & 0,530 & - & 0,851 & - & 0,047 & - \\
\hline
\end{tabular}

Nota: todas las medias son de una escala del 1 al 5.

Fuente: elaboración propia

Se encontró también que, mientras las mujeres de los videojuegos seleccionados, al igual que los hombres, hablan abiertamente de situaciones sexuales con muy poca regularidad, su discurso contiene más connotaciones sexuales implícitas, y su conducta no verbal también está más cargada de tintes sexuales. Esto pareciera apoyar la noción de la alta sexualización de la mujer en el videojuego, pero además nos da un nuevo matiz para esta discusión: ¿Es posible argumentar que la poca incidencia de lenguaje sexual explícito se deba también a una concepción cultural? En las representaciones tradicionales de la mujer seductora, es consistente la imagen de la misma como una figura que invita y propone de manera velada y sutil, seduciendo sin aceptarlo, pues no es su papel tomar el rol activo en un encuentro sexual: la representación sexualizada de la mujer, pues, no significa una liberación sexual de la misma, sino una mayor disposición a los intereses sexuales de su contraparte masculina. Más que un actor sexual, la mujer es representada como un objeto sexual, que atrae la acción del hombre. Bajo esta luz, la baja incidencia de lenguaje sexual explícito en comparación con las indirectas y lenguaje corporal parece ratificar la idea de una mujer sexualizada, pero no para su propio placer, sino en función del placer del género masculino.

Por otra parte, se encontró que los personajes femeninos son mostrados en actitudes de inseguridad con mayor frecuencia que los personajes masculinos, como se puede apreciar en la tabla 6. En una escala donde 5,0 sería un personaje que nunca muestra un solo indicio de inseguridad, la media de los personajes masculinos es de 4,14, mientras que la de los femeninos es de 3,51, con una significancia de 0,003. En lo que respecta a actitudes de liderazgo, los personajes masculinos también calificaron más alto. Por otro lado, se encontró que los personajes masculinos son mostrados en actitudes francamente ridículas con una frecuencia relativamente mayor que los personajes femeninos. 
Tabla 6. Prueba T, comportamiento de personajes masculinos y femeninos

\begin{tabular}{ccccccc}
\hline & \multicolumn{2}{c}{ Seguridad } & \multicolumn{2}{c}{ Actitud de liderazgo } & \multicolumn{2}{c}{ Comportamiento ridículo } \\
\hline & $N$ & Media & $N$ & Media & N & Media \\
\hline Sexo & & & & & & \\
\hline Masculino & 131 & $\mathbf{4 , 1 4}$ & 131 & 1,68 & 131 & $\mathbf{1 , 4 3}$ \\
\hline Femenino & 32 & 3,51 & 32 & 1,47 & 32 & 1,20 \\
\hline T & 2,38 & - & 1,14 & - & 2,08 & - \\
\hline Significancia & 0,022 & - & 0,256 & - & 0,040 & - \\
\hline
\end{tabular}

Nota: todas las medias son de una escala del 1 al 5.

Fuente: elaboración propia

La disparidad entre personajes masculinos y femeninos tanto en seguridad como en actitud de liderazgo parece reforzar las críticas que ha recibido la industria del videojuego por parte de la academia respecto a su constante representación de la mujer en papeles de damisela en apuros, histérica e indefensa, menos pronta a la acción que al llanto y al desconsuelo. Se podría argumentar que es este el aspecto más problemático de la estereotipación femenina tanto en medios tradicionales como en las nuevas plataformas: la percepción de la figura femenina como débil e indefensa. Este tipo de representación muy rara vez ofrece al receptor personajes femeninos dignos de admiración, a la vez que refuerza la visión patriarcal hegemónica, justificando el dominio del hombre en los aspectos importantes de la sociedad. La idea de la mujer como un miembro débil de la familia, la pareja y la sociedad, que debe ser protegido, justifica al patriarcado, llamándole protección en vez de dominio.

Cabe acotar aquí que ciertamente se puede observar en los videojuegos seleccionados un avance considerable respecto a lo encontrado por investigaciones enfocadas a generaciones anteriores de videojuegos. Si bien las mujeres aparecen más inseguras y menos proactivas que los hombres en estos títulos, ya no son presentadas de la manera caricaturizada encontrada por Provenzo (1991). Del mismo modo, aunque la sexualización de la mujer continúa, ya no se encuentra la cosificación flagrante descrita en el estudio de Glaubke et al. (2001). Aun cuando disten mucho de ser perfectos, los personajes femeninos de la séptima generación de videojuegos han ganado bastante terreno desde la princesa en apuros inútil e hipersexualizada encontrada frecuentemente por investigaciones hechas en generaciones anteriores del medio (Dietz, 1998; Provenzo, 1991). Este movimiento parece haber continuado en su avance desde la creación de los juegos analizados hasta la actualidad: personajes como Ellie en la serie The Last of Us - una coprotagonista hábil, segura, de identidad LGBT (Johnson, 2018) - nos da esperanza respecto a la dirección de la industria. 


\section{Conclusiones}

Se ha establecido en este reporte que la representación de género en los videojuegos de acción analizados es problemática tanto en su cantidad como en su calidad. El siguiente paso es comprender qué consecuencias puede tener dicha representación problemática. Para esto es necesario recuperar dos conceptos importantes: el otro lúdico y la agencia del jugador.

Los videojuegos, como ya se ha mencionado, son un medio interactivo y configurativo. Debido a estas características, muchos videojuegos requieren del jugador la identificación con los personajes que controla. Este proceso de identificación supone la creación momentánea de un yo lúdico, pero también, por proceso de eliminación y diferencia, conlleva el establecimiento de un otro lúdico (Corona, 2015): es decir, de todos aquellos personajes que representan, pero no me representan a mí (hablando desde la perspectiva del jugador). En el videojuego de acción, por otro lado, la diferencia de poder y agencia entre el avatar ${ }^{8}$ del jugador y los personajes no controlados por este es enorme. De esto se desprende que el videojuego, por el solo hecho de la elección del género, raza o nacionalidad de aquel o aquellos personajes que representarán al jugador, presenta un poderoso mensaje no solo respecto a la capacidad de agencia de esos grupos, sino también respecto a la agencia (o ausencia de ella) de las personas que no pertenecen a ellos (Corona, 2016). Las posibles consecuencias de lo anterior, a la luz de lo encontrado en esta investigación, merecen discutirse: la consecuencia más inmediata y aparente sería el hecho de que las jugadoras y jugadores de videojuegos se estarían enfrentando a universos diegéticos que no reflejan la diversidad y complejidad de las identidades femeninas en la realidad, y se verían forzados a reproducir, mediante la interacción con estos mundos, preconcepciones problemáticas respecto al género femenino. Por otro lado, si la identificación con el avatar en el acto de juego supone una comparación entre la agencia del personaje dentro del universo diegético del juego y la propia agencia social del jugador en el mundo real, y es de esta comparación que surge el disfrute de la sensación de empoderamiento (Corona, 2016), la ausencia de personajes femeninos como posibles avatares del jugador no solo obliga a las jugadoras a aceptar la falta de agencia del género femenino en el universo diegético del juego, sino que podríamos suponer que tiene el potencial de sugerir al jugador la esencialización de los contenidos problemáticos que estos videojuegos presentan como características comunes en el género femenino (sexualización, debilidad) y la falta de agencia de la mujer en el mundo real, lo cual claramente reproduciría el discurso hegemónico sobre las relaciones de poder entre géneros y resulta por demás problemático, aún como simple posibilidad.

Por otro lado, esta investigación se enfocó únicamente en el análisis de los videojuegos y los mensajes contenidos en estos. La lectura y uso que hace el jugador de los mismos, sin embargo, quedó fuera del alcance del estudio y merece ser retomada si de-

$8 \quad$ El término avatar se utiliza para denominar a aquella composición del espacio visual sobre el cual el jugador tiene control directo y al cual identifica como representante de sus acciones (Waggoner, 2009). Los personajes de Mario y Pac-Man, por ejemplo, son los avatares del jugador en sus respectivos videojuegos. 
seamos entender cuál es la relación entre estas representaciones y los significados que los usuarios extraen de ellas: es posible que una jugadora se oponga tajantemente a la representación de la mujer en Resident Evil 5, y que elija jugar la totalidad del juego como la deuteragonista africana Sheva Alomar, en vez de hacerlo como Chris Redfield, a quien el videojuego tácitamente propone como el protagonista, sin embargo, también es posible que dicha jugadora decida que este personaje femenino parece más débil, lo cual podría comprenderse como una clara desventaja en un videojuego cuya mecánica principal es la confrontación física. Ciertamente, el videojuego pareciera favorecer esta lectura.

La séptima generación de consolas de videojuegos tuvo su término informal como punta de lanza de la industria en los años 2012 y 2013, cuando los tres gigantes de la industria (Sony, Microsoft y Nintendo) lanzaron sus consolas de octava generación. Las consolas para las cuales se diseñaron los videojuegos aquí estudiados han alcanzado la obsolescencia, pero pareciera que se mantienen las tendencias esbozadas por los resultados aquí encontrados: por un lado, la continuación de los problemas en la cantidad y calidad de la representación de los personajes femeninos, por otro lado, la creciente concientización y autoanálisis de los creadores de la industria respecto a este problema. Si bien es cierto que desde el auge de los videojuegos aquí estudiados se han publicado títulos con protagonistas o deuteragonistas femeninos con representaciones mucho más empoderadas y diversas (como el caso de The Last of Us o del rediseño y replanteamiento de Lara Croft), también es cierto que los juegos que llevan a cabo estos avances no son representativos de la industria, y teniendo en cuenta el criterio de ventas, quedarían fuera del corpus si el estudio se replicara en la actualidad.

Si bien se han llevado a cabo un número considerable de investigaciones respecto a la representación identitaria en videojuegos, dichos estudios constituyen los primeros pasos hacia un estudio teórica y metodológicamente sólido de las representaciones identitarias en los videojuegos, a la luz del entendimiento adecuado de las características específicas de dicho medio. Hacen falta aún investigaciones de mayor profundidad y alcance para ahondar nuestro entendimiento de este medio y permitir una evaluación del papel del mismo en el entramado cultural contemporáneo. Es menester, sin embargo, que dichas investigaciones tengan en cuenta la naturaleza del videojuego y sus diferencias con otros medios de comunicación, si lo que buscamos es hacer un análisis eficaz y apropiado del fenómeno y sus alcances.

\section{Referencias}

Ashcroft, B., Griffiths, G. y Tiffin, H. (2013). Post-colonial studies: The key concepts. Londres: Routledge.

Beasley, B. y Standley, T. (2002). Shirts vs Skins: Clothing as an Indicator of Gender Role Stereotyping in Video Games. Mass Communication y Society, 5(3), 279-293.

Bogost, I. (2008). Unit Operations: An Approach to Videogame Criticism. Boston: MIT Press.

Bonder, G. (2002). Las nuevas tecnologías de información y las mujeres: reflexiones necesarias. Nueva York: United Nations Publications. 
Buró de Censos de Estados Unidos. (2016). Comparing 2015 American Community Survey Data. Recuperado de https://www.census.gov/programs-surveys/acs/guidance/comparing-acs-data/2015.html

Carlson, R. y Corliss, J. (2011). Imagined commodities: Video game localization and mythologies of cultural difference. Games and Culture, 6(1), 61-82.

Consalvo, M. (2006). Console video games and global corporations: Creating a hybrid culture. Nueva Media $y$ Society, 8(1). 117-137.

Corona, A. (2012). Jugando a ser blanco: Cantidad y calidad de la representación étnica en los videojuegos más vendidos de la séptima generación. Memorias del Encuentro de la Asociación Mexicana de Investigadores de la Comunicación (AMIC) 2012. (pp. 31-43). Saltillo, México: UAdeC

Corona, A. (2015). El otro lúdico: el problema de la representación de la otredad en el videojuego. Razón y Palabra, 92.

Corona, A. (2016). Videojuegos, identificación y agencia: por qué la diversidad no es suficiente. En G. Pérez Salazar (Ed.), Identidad, multiculturalidad y tecnologías de la información y la comunicación: cuatro aproximaciones desde la periferia. (pp.69-88). Saltillo: UAdeC / DeLaurel.

Corona, A. (2017). Minecraft y la ciudad: una propuesta para el uso de Minecraft como herramienta de análisis de la construcción de significado en espacios urbanos. En Ponencia presentada en el Encuentro de la Asociación Mexicana de Investigadores de la Comunicación (AMIC) 2017. Guanajuato, México. Recuperado de http://amic2015.uaq.mx/docs/2015_amic_convocatoria_ ponencias.pdf

De Certeau, M. (1984). The practice of everyday life. Berkeley: University of California.

Department of Defense. (2016). 2016 Demographics: Profile of the Military Community. Arlington: Department of Defense

Dempsey, N. (2017). UK Defence Personnel Statistics. Londres: House of Commons Library

Dietz, T. (1998). An examination of violence and gender role portrayals in video games: Implications for gender socialization and aggressive behavior. Sex Roles, 38(5/6) 425-442.

Díez, E., Fontal, O. y Blanco, D. (2004). Los videojuegos desde la perspectiva de género: roles y estereotipos. En el Foro de Tecnología Educativa y Atención a la Diversidad. Universidad de León. España.

Dill, K. y Thill, K. (2007). Video game characters and socialization of gender roles: Young people's perceptions mirror sexist media depictions. Sex Roles, 57, 851-664

Downs, E. y Smith, S. (2009) "Keeping Abreast of Hypersexuality: A Video Game Character Content Analysis". Sex Roles, 62(12), 721,733.

Dyer, N. y De Peuter, G. (2009). Games of Empire: Global Capitalism and Video Games. Minneapolis: University of Minnesota Press.

Egenfeldt, S., Smith, J.H. y Tosca, S. (2008). Understanding video games: the essential introduction. Londres: Routledge.

Entertainment Software Association (ESA). (2018). 2018 Sales, Demographic and Usage Data: Essential Facts. Recuperado de http://www.theesa.com/wp-content/uploads/2018/05/EF2018_FINAL.pdf

Fisher, H. (2015). Sexy, dangerous and ignored: An in-depth review of the representation of women in select video game magazines. Games and culture, 10(6), 551-570. 
Fiske, J. (1987). Television Culture, Londres: Methuen.

Fiske, J. (1991). Postmodernism and Television. En J. Curran y M. Gurevitch, (Eds.), Mass Media and Society (pp.55-67). Londres: E. Arnold Publishers

Frasca, G. (2004). Videogames of the Oppressed. First person: New Media as Story, Performance, and Game (pp. 85-94). Cambridge: MIT Press

Glaubke, C., Miller, P., Parker, M. y Espejo, E. (2001). Fair Play? Violence, Gender and Race in Video Games. Oakland: Children Now.

Hall, S. (1980). Encoding/Decoding. En S. Hall, D. hobson. A. Lowe y P. Willis (Eds.), Culture, Media, Language (pp. 90-103). Londres: Hutchinson.

Harrison, R., Drenten, J. y Pendarvis, N. (2016). Gamer Girls: Navigating a Subculture of Gender Inequality. En R. Belk (Ed.), Consumer Culture Theory (pp. 47-64). Bingley: Emerald Publishing.

Ip, B. (2010), Narrative structures in computer and video games: Part I: Context, definitions, and initial findings. Sage Journals, 6(2), 103-134.

Ip, B., y Jacobs, G. (2006). Quality function deployment for the games industry: Results from a practical application. Total Quality Management y Business Excellence, 17(7), 835-856.

Ivory, J. (2006). Still a Man's Game: Gender Representation in Online Reviews of Video Games. Mass Communication y Society, 9(1), 103-114.

Jenkins, H. (1992). Textual Poachers. Television Fans y Participatory Culture. Nueva York: Routledge.

Jensen, S. (2011). Othering, identity formation and agency. Qualitative Studies, 2(2), 63-78.

Johnson, A. (2018). The Las of Us 2 Ellie is First Openly LGBT Triple-A Protagonist. GameRevolution. Consultado el 8 de diciembre de 2018 en https://www.gamerevolution.com/news/396855-the-lastof-us-2-ellie-first-openly-lgbt-triple-a-protagonist

Kaplan, S. (2014). With \#GamerGate, the video-game industry's growing pains go viral. The Washington Post. Recuperado de https://www.washingtonpost.com/news/morning-mix/wp/2014/09/12/withgamergate-the-video-game-industrys-growing-pains-go-viral/

Kondrat, X. (2015). Gender and video games: ¿How is female gender generally represented in various genres of video games? Journal of Comparative Research in Anthropology and Sociology, 6(1), 171.

Krippendorff, K. (2004). Content analysis: an introduction to its methodology. Thousand Oaks: Sage.

Leonard, D. (2006). Not a Hater, Just Keepin' It Real: The Importance of Race- and Gender-Based Game Studies. Games and Culture, 1(1), 83-88.

Lynch, T., Tompkins, J., Van Driel, I., y Fritz, N. (2016). Sexy, strong, and secondary: A content analysis of female characters in video games across 31 years. Journal of Communication, 66(4), 564-584.

Malaby, T. (2007). Beyond play: A Nueva approach to games. Games and Culture, 2(2), 95-113.

Nichols R. (2013) Who Plays, Who Pays? Mapping Video Game Production and Consumption Globally. En N.B. Huntemann y B. Aslinger (eds) Gaming Globally. Critical Media Studies. Nueva York: Palgrave MacMillan

Newzoo. (2015). Newzoo. 2014 Global Games Market Report. Recuperado de https://newzoo.com/ news/newzoos-2014-global-games-market-report-available-now/ 
Newzoo. (2017). Newzoo. 2017 Global Games Market Report. Recuperado de https://newzoo.com/insights/ trend-reports/newzoo-global-games-market-report-2017-light-version/

Powell, J. y Menendian, S. (2016). The problem of Othering: towards inclusiveness and Belonging. Othering y Belonging, 1, 14-39.

Pro México. (2009). Creative industries in Mexico. Recuperado de http://www.promexico.gob.mx/ documentos/folletos-sectoriales/creative-industries.pdf

Provenzo, E. (1991). Video Kids: making sense of Nintendo. Cambridge: Harvard University Press.

Salen, K. y Zimmerman, E. (2004). Rules of Play: Game design fundamentals. Cambridge: The MIT Press.

Stuart, K. (2014). The Guardian. Gamergate: the community is eating itself but there should be room for all. Recuperado de https://www.theguardian.com/technology/2014/sep/03/gamergate-corruptiongames-anita-sarkeesian-zoe-quinn

Van Zoonen, L. (1991). Feminist perspectives on the media. Mass Media and Society, 33-54.

Waggoner, Z. (2009). My avatar, My Self: Identity in video role-playing games. Jefferson: McFarland.

Williams, D., Martins, N., Consalvo, M., e Ivory, J. (2009). The virtual census: Representations of gender, race and age in video games. Nueva Media y Society, 11(5), 815-834.

Zagal, J., Fernández-Vara, C. y Mateas, M. (2005). Gameplay Segmentation in Vintage Arcade Games. Ludologica Retro, 1, 1971-1984. 